\title{
Prism adaptation theory in unilateral neglect: motor and perceptual components
}

\author{
Styrmir Saevarsson * \\ Clinical Neuropsychology Research Group (EKN), Bogenhausen University Hospital, Munich, Germany \\ *Correspondence: styrmir.saevarsson@extern.Irz-muenchen.de
}

Edited by:

John J. Foxe, Albert Einstein College of Medicine, USA

Reviewed by:

James Danckert, University of Waterloo, Canada

Keywords: prism adaptation, motor component, perceptual component, assessment, theory, unilateral neglect

\section{A commentary on}

The influence of prism adaptation on perceptual and motor components of neglect: a reply to Saevarsson and Kristjánsson by Striemer, C. L., and Danckert, J. (2013). Front. Hum. Neurosci. 7:255. doi: 10.3389/ fnhum.2013.00255

Dissociating perceptual and motor effects of prism adaptation in spatial neglect

By Striemer, C., and Danckert, J. (2010a).

Neuroreport 21, 436-441. doi: 10.1097/ WNR.0b013e328338592f

Through a prism darkly: re-evaluating prisms and neglect

By Striemer, C., and Danckert, J. (2010b).

Trends Cogn. Sci. 14, 308-316. doi: 10.1016/

j.tics.2010.04.001

Striemer and Danckert (2010a) suggest that prism adaptation (PA) has beneficial effects primarily on spatial attention and the motor components of neglect, and that the direct effects on visual neglect are insignificant. The main support for their influential hypothesis (e.g., Saj et al., 2013) comes from their own study (Striemer and Danckert, 2010b), but Saevarsson and Kristjánsson (2013) criticize their interpretations, and call for another possible evaluation of their data. Striemer and Danckert (2013) reply to this criticism; however, there are a number of controversial and fundamental issues that remain unresolved in this debate which future empirical studies need to consider, to explain "how PA remediates symptoms of neglect" (Striemer and Danckert, 2013, p. 2).

Striemer and Danckert's (2010a) argument that PA primarily affects visuomotor and dorsal aspects of neglect, while leaving perceptual and ventral components of the syndrome mostly unaffected, underestimates the role of diagnosis and neuroanatomcial understanding of motor response deficits in unilateral neglect. Their main hypothesis is that PA improves visually guided actions but not perceptual biases that characterize neglect; however, this statement does not address the role of visual neglect in the therapeutic effects of PA. Even if the empirical findings of Striemer and Danckert (2010b) do not reveal positive effects on visual neglect, it is likely the deficit plays a passive role in improved directional motor response biases of unilateral neglect (premotor neglect: PMN). Indeed, the stronger visual unawareness is, the slower de-adaptation is, and vice versa (Michel et al., 2003, 2007; Goedert et al., 2010). Therefore, it is important to compare patients with motor response and visual neglect to visual neglect patients that do not suffer from motor aspects of neglect, in order to address the role of visual awareness following PA. Only by comparing these two groups can we explain the role of vision in PA. This contradicts Striemer and Danckert's claim that "whether the patient has been previously diagnosed as having "perceptual"or "premotor"neglect is largely irrelevant to interpreting the validity of the results." (Striemer and Danckert, 2013, p. 2). Furthermore, Saevarsson and Kristjánsson's (2013) interpretation assumes that directional movements in neglect are improved, while visual neglect prevents de-adaptation effects. This theory does not suggest that the effects can be prevented without visual neglect, as is inexactly claimed in Striemer and Danckert (2013). They highlight a lack of available data to evaluate the validity of the theory, even though it is based largely on the same data as their similar suggestion, although Saevarsson and Kristjánsson's (2013) interpretation is different.

The subtraction method applied by Striemer and Danckert (2010b) assumes that one can subtract directional hand movements from visual perception by applying verbal landmark and manual line bisection tasks. However, it is uncertain whether this is straight forward (Saevarsson, 2013). For instance, the landmark test requires a greater cognitive load than the line bisection task: Verbal processing and more working memory items versus simple hand movements and fewer items in working memory. An increased cognitive load has been found to cause patients to "freeze" while performing (Mattingley and Driver, 1997; Husain et al., 2000). These and similar tasks requiring line bisection responses reveal inconsistent findings (e.g., Harvey et al., 2002; Harvey and Olk, 2004). Moreover, Striemer and Danckert (2010b, p 436) claim the tasks to be "perceptually equivalent." This is questionable since the tasks are perceptually different: the landmark task is based on a pre-bisected vertical line, while line bisection is not (see e.g., Chiba et al., 2005; Saevarsson, 2013 for perceptually equivalent neglect tasks that require verbal and manual responses). Furthermore, as neglect is a multimodal deficit, it is better to test each modality one at a time, while the others are controlled, to avoid any possible misinterpretation or confounding variables (see Saevarsson, 2013 for a detailed discussion).

In support of their theory, Striemer and Danckert (2010a,b, 2013) note that neglect patients tend to gaze more often to the contralesional side following PA, 
although it does not produce improved perception (Dijkerman et al., 2003; Ferber et al., 2003). However, it is debated whether an increased number of contralateral eye movements in neglect following PA produces improved visual attention. Interestingly, the majority of studies maintain a contrary view (e.g., Rossetti et al., 1998; Angeli et al., 2004; Serino et al., 2006; Shiraishi et al., 2008; Vangkilde and Habekost, 2010). Additionally, Striemer and Danckert (2013) assert that they never intended to address PMN, but only motor behavior in neglect. Conversely, the response motor deficits of neglect are normally divided into two broad domains of premotor and motor neglect (e.g., Robertson and Halligan, 1999; Fink and Marshall, 2005; Saevarsson, 2013). Their study does not address motor neglect (Saevarsson, 2013), but rather directional and unilateral motor aspects of neglect (PMN). While Striemer and Danckert (2010b) measured directional motor deficit improvements with two classical PMN tasks (e.g., Bisiach et al., 1998; Harvey and Olk, 2004), the only reference they provide is Milner et al. (1993); a report on PMN (directional hypokinesia) testing which is based on a related paper from Bisiach et al. (1990). It is therefore unspecific to refer to general motor behavior aspects of the syndrome as it can, for example, refer to motor neglect, and it is uncertain how this can be applied in PA therapy and whether it differs from PMN. Further to this, Striemer and Danckert (2013) highlight that some authors doubt whether directional motor aspects of neglect are an important component of neglect syndrome (Himmelbach et al., 2007; Rossit et al., 2009). Nevertheless, most authors do not question the importance of PMN, but rather the way it is diagnosed (e.g., Mattingley and Driver, 1997; Marotta et al., 2003; Fink and Marshall, 2005; Coulthard et al., 2006; Punt and Riddoch, 2006; Goldenberg, 2010; Vallar and Mancini, 2010; Vossel et al., 2010; Loetscher et al., 2012; Saevarsson, 2013; see Saevarsson, 2013 for a detailed discussion on conceptual confusion of motor response deficits of neglect). Whether PMN belongs to the neglect syndrome or not it still needs to be addressed as it affects neglect performance.

\section{ACKNOWLEDGMENTS}

The author is grateful to Maria GutierrezHerrera and Hannah Pelikan for helpful discussion.

\section{REFERENCES}

Angeli, V., Benassi, M. G., and Làdavas, E. (2004). Recovery of oculo-motor bias in neglect patients after prism adaptation. Neuropsychologia 42, 1223-1234. doi: 10.1016/j.neuropsychologia.2004.01.007

Bisiach, E., Geminiani, G., Berti, A., and Rusconi, M. L. (1990). Perceptual and premotor factors of unilateral neglect. Neurology 40, 1278-1281. doi: 10.1212/WNL.40.8.1278

Bisiach, E., Ricci, R., Lualdi, M., and Colombo, M. R. (1998). Perceptual and response bias in unilateral neglect: two modified versions of the Milner Landmark Task. Brain Cogn. 37, 369-386. doi: 10.1006/brcg. 1998.1003

Chiba, Y., Yamaguchi, A., and Eto, F. (2005). A simple method to dissociate sensory-attentional and motor-intentional biases in unilateral visual neglect. Brain Cogn. 58, 269-273. doi: 10.1016/j.bandc.2005.01.002

Coulthard, E., Parton, A., and Husain, M. (2006) Action control in visual neglect. Neuropsychologia 44, 2717-2733. doi: 10.1016/j.neuropsychologia. 2005.11.004

Dijkerman, H. C., McIntosh, R. D., Milner, A. D., Rossetti, Y., Tilikete, C., and Roberts, R. C. (2003). Ocular scanning and perceptual size distortion in hemispatial neglect: effects of prism adaptation and sequential stimulus presentation. Exp. Brain Res. 153, 220-230. doi: 10.1007/s00221-0031595-1

Ferber, S., Danckert, J., Joanisse, M., Goltz, H. C., and Goodale, M. A. (2003). Eye movements tell only half the story. Neurology 60, 1826-1829. doi: 10.1212/01.WNL.0000061478.16239.5C

Fink, G. R., and Marshall, J. C. (2005). Motor aspects of neglect and related disorders. Aktuelle Neurol. 32, 594-603. doi: 10.1055/s-2004-834706

Goedert, K. M., Leblanc, A., Tsai, S. W., and Barrett, A. M. (2010). Asymmetrical effects of adaptation to left- and right-shifting prisms depends on pre-existing attentional biases. J. Int. Neuropsychol. 16, 795-804. doi: 10.1017/S13556 17710000597

Goldenberg, G. (2010). "The neuropsychological assessment and treatment of disorders of voluntary movement," in The Handbook of Clinical Neuropsychology, 2nd Edn., eds J. M. Gurd, U. Kischka, and J. C. Marshall (Oxford: Oxford University Press), 387-400. doi: 10.1093/acprof:oso/9780199234110.003.020

Harvey, M., Krämer-McCaffery, T., Dow, L., Murphy, P. J., and Gilchrist, I. D. (2002). Categorisation of "perceptual" and "premotor" neglect patients across different tasks: is there strong evidence for a dichotomy. Neuropsychologia 40, 1387-1395. doi: 10.1016/S0028-3932(01)00202-0

Harvey, M., and Olk, B. (2004). Comparison of the milner and bisiach landmark tasks: can neglect patients be classified consistently? Cortex 40, 659-665. doi: 10.1016/S0010-9452(08)70162-X

Himmelbach, M., Karnath, H. O., and Perenin, M. T. (2007). Action control is not affected by spatial neglect: a comment on Coulthard et al. Neuropsychologia 45, 1979-1981; discussion 1982-1984. doi: 10.1016/j.neuropsychologia.2006. 12.009

Husain, M., Mattingley, J. B., Rorden, C., Kennard, C., and Driver, J. (2000). Distinguishing sensory and motor biases in parietal and frontal neglect. Brain 123, 1643-1659. doi: 10.1093/brain/ 123.8.1643

Loetscher, T., Nicholls, M. E., Brodtmann, A., Thomas, N. A., and Brugger, P. (2012) Disentangling input and output-related components of spatial neglect. Front. Hum. Neurosci. 6:176. doi: $10.3389 /$ fnhum. 2012.00176

Marotta, J. J., McKeeff, T. J., and Behrmann, M. (2003). Hemispatial neglect: its effects on visual perception and visually guided grasping. Neuropsychologia 41, 1262-1271. doi: 10.1016/ S0028-3932(03)00038-1

Mattingley, J. B., and Driver, J. (1997). "Distinguishing sensory and motor deficits after parietal damage: an evaluation of response selection biases in unilateral neglect," in Parietal Contributions to Orientation in $3 D$ Space, eds P. Thier and H.-O. Karnath (Heidelberg: Springer), 309-338.

Michel, C., Pisella, L., Halligan, P. W., Luaute, J., Rode, G., Boisson, D., et al. (2003). Simulating unilateral neglect in normals using prism adaptation: implications for theory. Neuropsychologia 41, 25-39. doi: 10.1016/S0028-3932(02)00135-5

Michel, C., Pisella, L., Prablanc, C., Rode, G., and Rossetti, Y. (2007). Enhancing visuomotor adaptation by reducing error signals: single-step (aware) versus multiple-step (unaware) exposure to wedge prisms. J. Cogn. Neurosci. 19, 341-350. doi: 10.1162/jocn.2007.19.2.341

Milner, A. D., Harvey, M., Roberts, R. C., and Forster, S. V. (1993). Line bisection errors in visual neglect: misguided action or size distortion? Neuropsychologia 31, 39-49. doi: 10.1016/00283932(93)90079-F

Punt, T. D., and Riddoch, M. J. (2006). Motor neglect: implications for movement and rehabilitation following stroke. Disabil. Rehabil. 28, 857-864. doi: 10.1080/09638280500535025

Robertson, I. H., and Halligan, P. W. (1999). Spatial neglect: A clinical handbook for diagnosis and treatment. Hove: Psychology Press, 121-142.

Rossetti, Y., Rode, G., Pisella, L., Farné, A., Li, L., Boisson, D., et al. (1998). Prism adaptation to a rightward optical deviation rehabilitates left hemispatial neglect. Nature 395, 166-169. doi: $10.1038 / 25988$

Rossit, S., Malhotra, P., Muir, K., Reeves, I., Duncan, G., Livingstone, K., et al. (2009). No neglectspecific déficits in reaching tasks. Cereb. Cortex 19, 2616-2624. doi: 10.1093/cercor/bhp016

Saevarsson, S. (2013). Motor response deficits of unilateral neglect: assessment, therapy, and neuroanatomy. Appl. Neuropsychol. doi: 10.1080/090 84282.2012.710682. [Epub ahead of print].

Saevarsson, S., and Kristjánsson, A. (2013). A note on Striemer and Danckert's theory of prism adaptation in unilateral neglect. Front. Hum. Neurosci. 7:44. doi: 10.3389/fnhum.2013.00044

Saj, A., Cojan, Y., Vocat, R., Luauté, J., and Vuilleumier, P. (2013). Prism adaptation enhances activity of intact fronto-parietal areas in both 
hemispheres in neglect patients. Cortex 49, Striemer, C. L., and Danckert, J. (2013). The 107-119. doi: 10.1016/j.cortex.2011.10.009.

Serino, A., Angeli, V., Frassinetti, F., and Làdavas, E. (2006). Mechanisms underlying neglect recovery after prism adaptation. Neuropsychologia 44, 1068-1078. doi: 10.1016/j.neuropsychologia.2005.10.024

Shiraishi, H., Yamakawa, Y., Itou, A., Muraki, T., and Asada, T. (2008). Long-term effects of prism adaptation on chronic neglect after stroke. NeuroRehabilitation 23, 137-151.

Striemer, C. L., and Danckert, J. (2010a). Dissociating perceptual and motor effects of prism adaptation in neglect. Neuroreport 21, 436-441. doi: 10.1097/WNR.0b013e328338592f

Striemer, C. L., and Danckert, J. A. (2010b). Through a prism darkly: re-evaluating prisms and neglect. Trends Cogn. Sci. 14, 308-316. doi: 10.1016/j.tics.2010.04.001 influence of prism adaptation on perceptual and motor components of neglect: a reply to Saevarsson and Kristiánsson. Front. Hum. Neurosci. 7:255. doi: 10.3389/fnhum.2013. 00255

Vallar, G., and Mancini, F. (2010). "Mapping the neglect syndrome onto neurofunctional streams," in Perception, Action, and Consciousness. Sensorimotor Dynamics and Two Visual Systems (Oxford: Oxford University Press), 183-215.

Vangkilde, S., and Habekost, T. (2010). Finding Wally: prism adaptation improves visual search in chronic neglect. Neuropsychologia 48, 1994-2004. doi: 10.1016/j.neuropsychologia.2010. 03.020

Vossel, S., Eschenbeck, P., Weiss, P. H., and Fink, G. R. (2010). The neural basis of perceptual bias and response bias in the Landmark task. Neuropsychologia 48, 3949-3954. doi: 10.1016/j.neuropsychologia.2010.09.022

Received: 24 July 2013; accepted: 12 October 2013; published online: 05 November 2013.

Citation: Saevarsson S (2013) Prism adaptation theory in unilateral neglect: motor and perceptual components. Front. Hum. Neurosci. 7:728. doi: 10.3389/fnhum. 2013.00728

This article was submitted to the journal Frontiers in Human Neuroscience.

Copyright (c) 2013 Saevarsson. This is an open-access article distributed under the terms of the Creative Commons Attribution License (CC BY). The use, distribution or reproduction in other forums is permitted, provided the original author(s) or licensor are credited and that the original publication in this journal is cited, in accordance with accepted academic practice. No use, distribution or reproduction is permitted which does not comply with these terms. 